Editorial

\title{
Utilización de los biomarcadores en RM para una aproximación diagnóstica en los tumores cerebrales
}

\author{
Jorge Galíndez ${ }^{1}$ \\ ${ }^{1}$ Diagnóstico por Imágenes, Sanatorio Allende, Córdoba \\ Rev Argent Radiol 2021;85:1-2.
}

En el año 2016, la Organización Mundial de la Salud (OMS) publicó una nueva clasificación de los tumores cerebrales que incluía múltiples cambios significativos. Un número de tumores previamente reconocidos fueron redefinidos o hasta eliminados de la lista de clasificación, y también se agregaron nuevas entidades a esas listas. ${ }^{1}$

Antes de esta última actualización, la clasificación de los tumores cerebrales se basaba exclusivamente en su morfología histológica. En el sistema actualizado, se combinan parámetros fenotípicos y genotípicos, lo que agrega mayor objetividad para obtener diagnósticos más precisos que permiten mejorar el manejo del paciente desde el punto de vista pronóstico y la correcta elección de su tratamiento. ${ }^{1,2}$

En el trabajo "Biomarcadores radiológicos en RM para una aproximación al diagnóstico molecular en gliomas IDHmutados (grado II y III)", publicado en este número, los autores realizan una investigación retrospectiva analizando las características imagenológicas en resonancia magnética (RM), utilizando secuencias que se encuentran disponibles en todos los equipos de RM como el T2, FLAIR y SWI, lo que otorga a este tipo de estudios alta reproducibilidad, en un grupo específico de tumores de la actual clasificación de la OMS, que son los gliomas difusos. ${ }^{3}$

Los gliomas difusos actualmente se presentan como un grupo heterogéneo de tumores que incluyen los grados II y III (astrocíticos $\mathrm{u}$ oligodendrogliales) $\mathrm{y}$ el grado IV (glioblastoma) con peor pronóstico. En el trabajo previamente citado, se hace referencia particularmente a los grados II y III, los cuales son altamente frecuentes en la edad adulta. ${ }^{2,4}$

Los gliomas grado II y III comparten características comunes en relación a las mutaciones genéticas del gen Isocitrato Dehidrogenasa (IDH), tanto en el IDH1 como en el IDH2. Asimismo, estos gliomas de bajo grado se diferencian molecularmente entre sí, lo que les otorga características propias. $^{4}$

Los autores lograron desarrollar un trabajo en el que, de manera sencilla y práctica, agruparon características morfológicas en los estudios de RM con secuencias básicas para intentar predecir el tipo de expresión genética, y en lo posible el subgrupo molecular de estos gliomas de bajo grado. Esta información es de suma importancia para el médico tratante por su impacto en el pronóstico, y lo encamina hacia las terapias más efectivas en cada caso.

Entre los biomarcadores radiológicos estudiados, se destaca el signo del mismatch T2-FLAIR, el cual ha demostrado ser altamente específico para el diagnóstico de los gliomas difusos IDH-mutados 1p/19q no codelecionados. Hay que saber que, si bien este signo no es $100 \%$ específico, la evidencia actual continúa otorgándole alta especificidad y valor predictivo positivo para el diagnóstico de los tumores gliales previamente citado. ${ }^{4,5}$

Esta presentación es útil también para introducir a los radiólogos en un tema que cada día gana mayor importancia en la práctica médica y del que se desprenden múltiples aristas de investigación, que se conoce como radiogenómica. ${ }^{6}$

La radiogenómica es una nueva herramienta en la investigación contra el cáncer que se ocupa de analizar la relación entre los fenotipos imagenológicos y la genómica de los tumores. Es un instrumento que podría ser de suma importancia cuando no se dispone de laboratorios genéticos altamente especializados, donde el análisis de las imágenes aporta los mayores datos para dilucidar el comportamiento molecular de los tumores y así guiar al médico tratante para determinar el pronóstico y definir la mejor estrategia terapéutica. ${ }^{6}$
Address for correspondence Jorge Galíndez, Diagnóstico por Imágenes, Sanatorio Allende, Córdoba

(e-mail: jagalindez47@gmail. com).
DOI https://doi.org/ 10.1055/s-0041-1725092. ISSN 1852-9992.
(C) 2021. Asociación Civil Sociedad Argentina de Radiología and Federacion Argentina de Asociaciones de Radiología, Diagnóstico por Imágenes y Terapia Radiante. All rights reserved.

This is an open access article published by Thieme under the terms of the Creative Commons Attribution-NonDerivative-

NonCommercial-License, permitting copying and reproduction so long as the original work is given appropriate credit. Contents may not be used for commercial purposes, or adapted, remixed, transformed or built upon. (https:// creativecommons.org/licenses/by-nc-nd/4.0/) Thieme Revinter Publicações Ltda., Rua do Matoso 170, Rio de Janeiro, RJ, CEP 20270-135, Brazil 


\section{Editorial}

\section{Bibliografía}

1 Louis DN, Perry A, Reifenberger G, von Deimling A, FigarellaBranger D, Cavenee WK, et al. The 2016 World Health Organization Classification of Tumors of the Central Nervous System: a summary. Acta Neuropathol. 2016;131(06):803-820

2 Johnson DR, Guerin JB, Giannini C, Morris JM, Eckel LJ, Kaufmann TJ. 2016 Updates to the WHO Brain Tumor Classification System: What the Radiologist Needs to Know. Radiographics. 2017;37 (07):2164-2180

3 Darakdjian M, Osa Sanz E, Hernández Pinzón J, Carnevale M, Diebel A, Arakaki N. Biomarcadores radiológicos en RM para una aproximación al diagnóstico molecular en gliomas IDH-mutados (grado II y III). Rev Argent Radiol. 2021;85(01):02-09

4 Patel SH, Poisson LM, Brat DJ, Zhou Y, Cooper L, Snuderl M, et al. T2-FLAIR Mismatch, an Imaging Biomarker for IDH and 1p/19q Status in Lower-grade Gliomas: A TCGA/TCIA Project. Clin Cancer Res. 2017;23(20):6078-6085

5 Johnson DR, Kaufmann TJ, Patel SH, Chi AS, Snuderl M, Jain R. There is an exception to every rule-T2-FLAIR mismatch sign in gliomas. Neuroradiology. 2019;61(02):225-227

6 Mazurowski MA. Radiogenomics: what it is and why it is important. J Am Coll Radiol. 2015;12(08):862-866 